\title{
Pode o etiltrinexapac estimular o crescimento de mudas de eucalipto?
}

\author{
Can trinexapac-ethyl stimulate the initial growth of eucalyptus? \\ Rodrigo Neto Pires ${ }^{\mathrm{I}}$, Allan Lopes Bacha ${ }^{\mathrm{II}}$, Mariluce Pascoina Nepomuceno ${ }^{\mathrm{III}}$, \\ Pedro Luis da Costa Aguiar Alves ${ }^{\mathrm{IV}}$
}

\begin{abstract}
Resumo
Reguladores vegetais e herbicidas atuam e modificam diversos processos metabólicos nas plantas. A aplicação de doses subletais destes compostos pode ser utilizada de modo a modular o desenvolvimento e o crescimento das plantas, um efeito denominado hormesis. Múltiplos estudos têm relatado o efeito promotor de doses subletais de etiltrinexapac no acúmulo de biomassa e na expansão da área foliar de plantas de eucalipto. Até o presente momento, não há recomendação acerca de doses promotoras e/ou inibidoras de processos metabólicos para a cultura do eucalipto. Desta forma, este trabalho teve como objetivo investigar o efeito de doses crescentes de etiltrinexapac no estabelecimento e crescimento inicial de mudas de Eucalyptus urograndis. Etiltrinexapac foi aplicado em doses de 15 a $90 \mathrm{~g}$ de ingrediente ativo por hectare $\left(\mathrm{g}\right.$ i.a. $\left.\mathrm{ha}^{-1}\right)$, em duas modalidades, através da pulverização ou da imersão das raízes em solução. As doses de $15 \mathrm{~g}$ i.a. ha ${ }^{-1}$ via pulverização, e $30 \mathrm{~g}$ i.a. ha ${ }^{-1}$ via imersão de raízes, resultaram em efeito positivo no crescimento do clone GG100 de Eucalyptus urograndis, com acréscimos de, respectivamente, $74,6 \%$ e $12,8 \%$ na massa seca total, em relação à testemunha. As doses de 15 a 90 g i.a. ha ${ }^{-1}$, via pulverização, resultaram em efeito estimulatório no crescimento do eucalipto. As doses de 15 e $30 \mathrm{~g}$ i.a. ha ${ }^{-1}$, na modalidade imersão das raízes, proporcionaram efeito positivo nas características avaliadas do eucalipto. A dose de $90 \mathrm{~g}$ i.a. ha $^{-1}$ apresentou efeito inibitório ao crescimento do eucalipto na modalidade imersão das raízes, aos 35 dias após a aplicação de etiltrinexapac.
\end{abstract}

Palavras-chave: Eucalyptus urograndis; Efeito hormético; Dose-resposta; Doses subletais

\begin{abstract}
Plant growth regulators and herbicides can act and modify several metabolic processes in plants. The use of sub-lethal doses of those compounds might modulate the development and growth of plants, an effect known as hormesis. Recent studies reported the stimulatory responses of sub-lethal doses of trinexapac-ethyl on the biomass accumulation and leaf area expansion of eucalypt plants. To date, there is no recommendation regarding promoting or inhibitory doses of such compounds for eucalypt production industry. Thus, this work aims to investigate the effect of trinexapac-ethyl on the establishment and initial growth of Eucalyptus urograndis seedlings. Trinexapacethyl was applied at doses varying 15 to $90 \mathrm{~g}$ (plus a control treatment) per hectare of active ingredient ( $\left.\mathrm{g} \mathrm{a.i.} \mathrm{ha}{ }^{-1}\right)$ in two application methods: spraying and root immersion. The doses of $15 \mathrm{~g}$ a.i. ha ${ }^{-1}$ through spraying and the $30 \mathrm{~g}$ a.i. $\mathrm{ha}^{-1}$ in root immersion resulted in a positive effect on the growth of Eucalyptus urograndis Clone GG100. Total dry biomass increased by $74.6 \%$ and $12.8 \%$, respectively, compared to control plants. The spraying of 15 to $90 \mathrm{~g}$ a.i. ha ${ }^{-1}$ of trinexapax-ethyl resulted in a stimulatory effect on the growth of eucalyptus. The doses of 15 and $30 \mathrm{~g}$ a.i. ha ${ }^{-1}$ via root immersion provided a positive effect on the all evaluated characteristics of eucalyptus. The dose of $90 \mathrm{~g}$ a.i. ha- ${ }^{-1}$ resulted in an inhibitory effect on eucalyptus growth through root immersion at 35 days after the trinexapac-ethyl application.
\end{abstract}

Keywords: Eucalyptus urograndis; Hormesis; Dose-response; Sub-lethal doses

\footnotetext{
I Biólogo, MSc., Doutorando em Plant Sciences, The University of Western Australia, School of Biological Sciences, Faculty of Science, 35, Stirling Highway, Crawley, 6009, Perth, Australia. rneto.pires@gmail.com (ORCID: 0000-0001-7384-6849)

II Biólogo, MSc., Doutorando em Produção Vegetal, Faculdade de Ciências Agrárias e Veterinárias, Universidade Estadual Paulista, Via de Acesso Prof. Paulo Donato Castellane, s/n, CEP 14884-900, Jaboticabal (SP), Brasil. allan_lb@hotmail.com (ORCID: 0000-0002-5506-6766)

III Engenheira Agrônoma, Doutora em Produção Vegetal, Faculdade de Ciências Agrárias e Veterinárias, Universidade Estadual Paulista, Via de Acesso Prof. Paulo Donato Castellane, s/n, CEP 14884-900, Jaboticabal (SP), Brasil. mariluce_n@hotmail.com (ORCID: 0000-0002-96190325)

IV Engenheiro Agrônomo, Dr., Professor do Departamento de Biologia Aplicada à Agropecuária, Faculdade de Ciências Agrárias e Veterinárias, Universidade Estadual Paulista, Via de Acesso Prof. Paulo Donato Castellane, s/n, CEP 14884-900, Jaboticabal (SP), Brasil. plalves@fcav. unesp.br (ORCID: 0000-0003-2348-2121)
} 


\section{Introdução}

O sucesso de um empreendimento florestal é alcançado quando a produção de mudas, a implantação e a formação inicial da floresta são feitas de maneira correta, buscando-se conhecer e desenvolver mais eficientemente os processos envolvidos nas etapas produtivas. A formação inicial da floresta, desde o viveiro até o plantio, envolve diversos fatores e condiciona o estabelecimento das plantas no campo, devido à boa formação de raízes e novas brotações, bem como à resistência a estresses bióticos e abióticos. O Brasil apresenta mais de 5,6 milhões de hectares de florestas plantadas com eucalipto em diversos estados da federação, alcançando importante relevância na economia do país, sendo que o setor florestal representou 1,2\% do PIB nacional no ano de 2015 (INDÚSTRIA BRASILEIRA DE ÁRVORES, 2016). Além da extensa área ocupada pelos eucaliptais, também se destaca a grande produtividade das florestas brasileiras, com valores de $36 \mathrm{~m}^{3} \mathrm{ha}^{-1}$ ano-1 durante o ano de 2015, sendo o país com a maior produtividade do mundo (INDÚSTRIA BRASILEIRA DE ÁRVORES, 2016). Desta forma, deve-se estar atento aos fatores que possam causar estresse às plantas e impactar direta ou indiretamente a produtividade da eucaliptocultura.

Uma alternativa para se garantir o sucesso do empreendimento florestal, é a aplicação de compostos, originalmente utilizados como herbicidas e/ou reguladores vegetais e que, em subdoses, podem auxiliar no crescimento e desenvolvimento das plantas. Este efeito, conhecido como hormesis, ou efeito hormético (CALABRESE; BALDWIN, 2002), foi introduzido por Southam e Erlich (1943) e vem sendo amplamente discutido e pesquisado com o objetivo de se compreender o mecanismo de ação estimulante e benéfico de diversas substâncias, inicialmente consideradas tóxicas ou inibitórias em doses elevadas (CEDERGREEN; OLESEN, 2010; CARVALHO; ALVES; DUKE, 2013; BELZ; DUKE, 2014).

O glyphosate tem sido utilizado em diversos trabalhos investigando o efeito hormético e as dosesresposta para a aplicação em eucalipto (VELINI et al., 2008; PEREIRA et al., 2013), contudo, há carência de trabalhos na literatura que tenham como objetivo identificar outros compostos capazes de promover hormesis em culturas de interesse, bem como estudos que avaliem as doses capazes de gerar estímulos, e quais características seriam beneficiadas com esta aplicação. Dentre os compostos que podem promover a hormesis, uma opção potencial de uso é o etiltrinexapac (PIRES et al., 2013; BACHA et al., 2017). Este composto é um regulador vegetal do tipo II, comumente utilizado para reduzir o crescimento vegetativo de gramados e cereais. Os reguladores do tipo II atuam como inibidores da biossíntese de giberelinas, interrompendo o alongamento celular (ERVIN; KOSKI, 2001).

Adams et al. (1992) ressaltam que o mecanismo de ação do etiltrinexapac está relacionado com a inativação da enzima $\mathrm{GA}_{20} 3 \beta$-hydroxilase, devido à competição entre o regulador vegetal e o 2-oxogluterato pelo substrato metabólico (i.e. $\mathrm{Fe}^{+2} /$ ascorbato-dependente dioxygenase), consequentemente, reduzindo o nível de giberelinas ativas, principalmente GA. Em estudo realizado por Pires et al. (2013), constatou-se que a aplicação de subdoses de etiltrinexapac resultou no aumento da área foliar, diâmetro do caule e da massa seca das plantas de eucalipto. A aplicação de $15 \mathrm{~g}$ i.a. ha ${ }^{-1}$ do maturador resultou em cerca de $15 \%$ de incremento para todas as características avaliadas (e.g. massa seca de folhas e do caule e diâmetro do caule) com exceção da área foliar. Para esta característica, a dose de $20 \mathrm{~g}$ i.a. ha ${ }^{-1}$ resultou em estímulo de $20 \% \mathrm{em}$ relação às plantas de eucalipto não tratadas.

A avaliação desta nova forma de aplicação de produtos, que antes eram utilizados somente com o objetivo de se reduzir o ritmo de crescimento ou inibir o desenvolvimento vegetativo das culturas, tornase pauta interessante, pois o estímulo produzido pela aplicação de herbicidas e reguladores vegetais em subdoses tem promovido aumentos significativos em parâmetros importantes na produção de mudas de eucalipto. Com base nestas informações, objetivou-se avaliar o efeito de subdoses de etiltrinexapac, por meio da pulverização foliar ou imersão de raízes, no crescimento inicial de mudas de Eucalyptus urograndis.

\section{Materiais e Métodos}

\section{Local e caracterização dos materiais}

O experimento foi instalado e conduzido em área aberta, sob condições semicontroladas, nas dependências do Laboratório de Plantas Daninhas (LAPDA) do Departamento de Biologia Aplicada à 
Agropecuária, pertencente à Faculdade de Ciências Agrárias e Veterinárias - FCAV/UNESP - Campus de Jaboticabal, São Paulo, Brasil, cujas coordenadas geográficas são latitude $21^{\circ} 15^{\prime} 17^{\prime}$ "S, longitude $48^{\circ} 19^{\prime} 20^{\prime \prime} \mathrm{W}$ e altitude de $590 \mathrm{~m}$. O clima da região, segundo classificação Köppen, é do tipo Cwa, subtropical, seco no inverno, com chuvas de verão, apresentando temperatura média anual de $22^{\circ} \mathrm{C}$ e precipitação de $1.552 \mathrm{~mm}$. As atividades deste trabalho foram realizadas entre os meses de fevereiro e abril de 2014.

Para a realização do experimento, foram utilizadas mudas do clone comercial GG100 de E. urograndis, resultante do cruzamento entre E. grandis W. Hill ex. Maiden com E. urophylla S.T. Blake, adquiridas no viveiro Agriflora ${ }^{\circledR}$, localizado no município de Araraquara, São Paulo. O maturador utilizado foi o produto comercial Moddus ${ }^{\circledR}$, da classe dos reguladores de crescimento vegetal do grupo químico ácido dioxociclohexanocarboxílico, de formulação concentrada emulsionável, da companhia Syngenta ${ }^{\circledR}$ Proteção de Cultivos Ltda. O produto é composto por $250 \mathrm{~g} \mathrm{~L}^{-1}$ do ingrediente ativo etiltrinexapac.

\section{Delineamento experimental e aplicação do maturador}

Foi utilizado delineamento experimental inteiramente casualizado e os tratamentos foram arranjados em esquema fatorial $2 \times 6+1$, sendo duas modalidades de aplicação (imersão das raízes e pulverização da parte aérea) x seis doses do etiltrinexapac e um tratamento controle. As doses de 15, 30, 45, 60, 75, e 90 g i.a. ha ${ }^{-1}$ de etiltrinexapac foram estabelecidas de acordo com experimentos previamente realizados por Pires et al. (2013), e determinadas para a discriminação de doses promotoras e inibidoras do desenvolvimento das plantas de eucalipto. As doses do maturador foram aplicadas no eucalipto antecedendo o plantio das mudas nos vasos, por meio de pulverização foliar, ou por imersão das raízes em solução com o produto, ainda com as plantas acondicionadas em tubetes. As plantas-controle foram pulverizadas com água assim como a imersão das raízes também feita em água.

Para a pulverização, foi utilizado um pulverizador costal à pressão constante $\left(\mathrm{CO}_{2}\right)$, munido de barra com quatro pontas XR 110.02 regulado para gasto de volume de calda de $200 \mathrm{~L} \mathrm{ha}^{-1}$. Antecedendo à imersão das raízes, foi realizada uma curva de embebição, de forma a determinar o tempo mínimo necessário para que as raízes pudessem absorver o maturador diluído na água. Para tanto, foram utilizadas mudas $(\mathrm{n}=8)$ previamente identificadas, que se encontravam sem irrigação por um período de 12 horas, as quais foram colocadas em uma caixa com um suporte de material isopor, previamente preenchida com $6 \mathrm{~L}$ de água. A partir deste momento, a cada dez minutos, foram realizadas pesagens, com objetivo de se verificar quanto de massa (quantidade de água absorvida) as plantas ganhariam até a estabilização. Determinou-se que o tempo necessário para a embebição das raízes foi de, no mínimo, 30 minutos. De acordo com a metodologia anteriormente descrita, a imersão das raízes foi realizada utilizando-se seis litros de solução de etiltrinexapac por caixa/tratamento.

Após 12 horas da aplicação do etiltrinexapac, as mudas foram transplantadas, sendo cada vaso com uma planta de eucalipto considerado uma parcela experimental. Foram utilizados vasos com capacidade para $10 \mathrm{~L}$, previamente preenchidos com terra coletada da camada arável de um Neossolo Quartazarênico (Areia Quartzosa). Após o plantio e durante todo o período experimental, as mudas foram irrigadas diariamente até capacidade de campo.

\section{Avaliação do crescimento}

Antecedendo as aplicações, foram amostradas aleatoriamente seis mudas de eucalipto para a caracterização quanto à altura e diâmetro do caule, área foliar (AF), bem como a massa seca das raízes (MSR) e a massa seca total (MST). A altura das plantas foi determinada com uma régua milimetrada, medida do nível do substrato até a gema apical. O diâmetro do coleto foi determinado com um paquímetro digital $30 \mathrm{~mm}$ acima do solo. A área foliar foi determinada com o medidor de área foliar de bancada (LI 3000A, LI-COR Biosciences). As massas secas foram obtidas após a secagem dos materiais em estufa com circulação forçada de ar sob temperatura de $70^{\circ} \mathrm{C}$ até peso constante. As mudas selecionadas apresentavam, em média: $20,7 \pm 5 \mathrm{~cm}$ de altura; $3,37 \pm 1,7 \mathrm{~mm}$ de diâmetro do caule; $116,8 \pm 41,8 \mathrm{~cm}^{2} \mathrm{de} A F ; 0,55 \pm 0,22$ $\mathrm{g}$ de MSR; e 2,53 $\pm 0,8 \mathrm{~g}$ de MST.

As avaliações foram realizadas aos 7, 14, 21, 28 e 35 dias após a aplicação (DAA) do etiltrinexapac, 
caracterizando as plantas quanto à altura e diâmetro do caule. Aos 35 DAA, final do período experimental, foram avaliadas as mesmas características anteriormente citadas na caracterização inicial das mudas.

Análise dos dados

Os dados foram submetidos à análise de variância pelo teste $\mathrm{F}$, comparando-se as modalidades de aplicação, de maneira a identificar a modalidade que obteve as melhores respostas para cada variável analisada. As médias foram comparadas pelo teste de Tukey ao nível $5 \%$ de probabilidade com o auxílio do software estatístico AgroEstat (versão 1.1.0.626). Entre as doses de etiltrinexapac foram feitas análises de regressão, seguindo o modelo polinomial, utilizando-se o software MicroCal Origin Pro v. 8 para a construção dos gráficos.

\section{Resultados e Discussão}

Aos 7 e 14 dias não foram constatadas diferenças significativas entre os tratamentos, sendo mensuráveis os efeitos da aplicação partir dos 21 DAA. Entretanto, as respostas obtidas aos 21 e 28 DAA foram similares às avaliadas aos 35 DAA, e desta forma, somente foram apresentados os resultados da avaliação final, os quais refletiram o comportamento das plantas ao longo do período experimental. Com exceção das concentrações de 15, 30 e 45 g i.a. ha ${ }^{-1}$, as doses aplicadas via pulverização foliar resultaram em maior crescimento em altura em relação à modalidade de aplicação via imersão de raízes (Tabela 1-A). Na pulverização foliar do etiltrinexapac, verificou-se que todas as doses proporcionaram um aumento do crescimento das plantas de eucalipto. Quando comparadas com as plantas-controle, a dose de 60 g i.a. ha ${ }^{-1}$ apresentou o melhor resultado, proporcionando $12,8 \%$ de incremento na altura das mudas de eucalipto (Figura 1-A). Apesar do etiltrinexapac ser recomendado como um redutor do crescimento em altura de algumas espécies, principalmente em cereais (RAJALA et al., 2002), o efeito decorrente da aplicação do maturador resultou em efeito promotor para esta característica do eucalipto, corroborando resultados recentes observados por Bacha et al. (2017).

Para a modalidade de imersão das raízes, a dose de $30 \mathrm{~g}$ i.a. ha- ${ }^{-1}$ foi a que obteve melhores resultados, com $9,4 \%$ de incremento em altura das plantas de eucalipto, quando comparados às plantascontrole. A aplicação de $90 \mathrm{~g}$ i.a. ha ${ }^{-1}$ não resultou em estímulo ou inibição quando comparada ao resultado observado para as plantas-controle, contudo, quando comparada à dose de $30 \mathrm{~g}$ i.a. ha ${ }^{-1}$, observou-se redução de 5,4\% na altura das plantas de eucalipto (Figura 1-A).

O efeito promotor na altura das plantas de eucalipto após a aplicação do maturador, pode ser resultado da alteração no balanço hormonal com favorecimento da ação da citocinina, ácido abscísico ou auxina, hormônios estes responsáveis pela sinalização do crescimento e desenvolvimento nas plantas (TAIZ; ZAIGER, 2013). Além disso, Rademacher (2016) ressalta que em alguns casos, pode haver um efeito paradoxal do etiltrinexapac, uma vez que o esperado seria um efeito deletério do produto, devido à inativação da conversão de $\mathrm{GA}_{20}$ (giberelina inativa) em $\mathrm{GA}_{1}$ (giberelina bioativa). No entanto, foi provado que além de evitar a hidroxilação na posição $3 \beta$, para a formação de GA 1 (ADAMS et al., 1992), o etiltrinexapac também inibe a hidroxilação na posição $2 \beta$, evitando com que as giberelinas

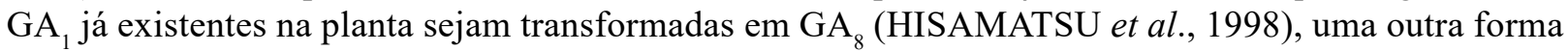
inativa do composto. Com isso, possivelmente, a maior permanência das giberelinas na forma $\mathrm{GA}_{1}$ fez com que fossem observados efeitos promotores nas mudas de eucalipto.

Para o diâmetro do caule, verificou-se que a pulverização resultou em maiores estímulos do que a imersão das raízes, independentemente da dose de etiltrinexapac aplicada (Tabela 2). Para todas as doses aplicadas através da pulverização, observou-se que o padrão de crescimento do diâmetro foi o mesmo das plantas-controle, sendo esta a variável menos sensível à aplicação do etiltrinexapac (Figura 1-B). Já para a imersão das raízes, houve uma tendência de decréscimo no diâmetro do caule principalmente para a dose de $90 \mathrm{~g}$ i.a. ha $\mathrm{h}^{-1}$ (Figura 1-B). 
Tabela 1 - Desdobramento da interação modalidade de aplicação $x$ doses de etiltrinexapac sobre a altura (cm), área foliar $\left(\mathrm{cm}^{2}\right)$, massa seca da raiz $(\mathrm{g})$ e massa seca total das mudas $(\mathrm{g})$ de eucalipto aos 35 dias após a aplicação. Jaboticabal-SP, 2014.

Table 1 - Interactions between the application modalities $\mathrm{x}$ trinexapac-ethyl doses on the height $(\mathrm{cm})$, leaf area $\left(\mathrm{cm}^{2}\right)$ root dry mass $(\mathrm{g})$ and total dry mass $(\mathrm{g})$ of eucalyptus seedlings at 35 days after application. Jaboticabal, São Paulo state, 2014.

\begin{tabular}{|c|c|c|c|c|c|c|c|c|}
\hline \multirow{3}{*}{ Modalidade } & \multicolumn{7}{|c|}{ Doses (g i.a. ha-1) } & \multirow{3}{*}{$\mathbf{F}$} \\
\hline & $\mathbf{0}$ & 15 & 30 & 45 & 60 & 75 & 90 & \\
\hline & \multicolumn{7}{|c|}{ (A) - Altura (cm) } & \\
\hline Pulverização & $39,5 \mathrm{Ab}$ & $42,4 \mathrm{Aa}$ & $42,6 \mathrm{Aa}$ & $43,2 \mathrm{Aa}$ & $44,2 \mathrm{Aa}$ & $43,2 \mathrm{Aa}$ & $43,6 \mathrm{Aa}$ & $7,28 * *$ \\
\hline Imersão & $\begin{array}{l}40,3 \\
\mathrm{Abc}\end{array}$ & $41,6 \mathrm{Ab}$ & $44,1 \mathrm{Aa}$ & $\begin{array}{l}42,0 \\
\mathrm{Aab}\end{array}$ & 42,4 Bab & $40,6 \mathrm{Bbc}$ & $38,7 \mathrm{Bc}$ & $9,29 * *$ \\
\hline $\mathrm{F}$ & $1,03^{\mathrm{ns}}$ & $1,09^{\mathrm{ns}}$ & $3,45^{\mathrm{ns}}$ & $2,49^{\mathrm{ns}}$ & $5,26^{*}$ & $11,0^{* *}$ & $38,1 * *$ & ----- \\
\hline
\end{tabular}

(B) - Área Foliar $\left(\mathrm{cm}^{2}\right)$

\begin{tabular}{|c|c|c|c|c|c|c|c|c|}
\hline Pulverização & $\begin{array}{c}278,3 \\
\text { Ac }\end{array}$ & $467,8 \mathrm{Aa}$ & $\begin{array}{c}382,3 \\
\mathrm{Ab}\end{array}$ & $\begin{array}{c}388,6 \\
\mathrm{Ab}\end{array}$ & $406,1 \mathrm{Ab}$ & 409,1 Aab & $369,4 \mathrm{Ab}$ & $16,4^{* *}$ \\
\hline Imersão & $\begin{array}{c}220,9 \\
\mathrm{Bb}\end{array}$ & $245,6 \mathrm{Bab}$ & $\begin{array}{c}285,5 \\
\mathrm{Ba}\end{array}$ & $\begin{array}{c}203,9 \\
\mathrm{Bb}\end{array}$ & $230,7 \mathrm{Bab}$ & $230,1 \mathrm{Bab}$ & $135,1 \mathrm{Bc}$ & $10,6^{* *}$ \\
\hline $\mathrm{F}$ & $8,31 * *$ & $124,8^{* *}$ & $23,6^{* *}$ & $86,2 * *$ & $77,6^{* *}$ & $80,9 * *$ & $138,8^{* *}$ & ----- \\
\hline
\end{tabular}

(C) - Massa Seca da Raiz (g)

\begin{tabular}{lcccccccc}
\hline Pulverização & $1,38 \mathrm{Bd}$ & $2,51 \mathrm{Aa}$ & $\begin{array}{c}1,94 \\
\mathrm{Abc}\end{array}$ & $\begin{array}{c}1,70 \\
\mathrm{Acd}\end{array}$ & $1,84 \mathrm{Abc}$ & $2,21 \mathrm{Aab}$ & $1,98 \mathrm{Abc}$ & $13,9^{* *}$ \\
Imersão & $1,67 \mathrm{Aa}$ & $1,58 \mathrm{Bab}$ & $1,71 \mathrm{Aa}$ & $1,15 \mathrm{Bc}$ & $1,31 \mathrm{Babc}$ & $1,17 \mathrm{Bbc}$ & $0,67 \mathrm{Bd}$ & $14,5^{* *}$ \\
& & & & & & & & \\
$\mathrm{~F}$ & $4,62^{*}$ & $45,6^{*}$ & $2,79^{\text {ns }}$ & $16,2^{* *}$ & $14,7^{* *}$ & $58,1^{* *}$ & $91,1^{* *}$ & $-\cdots$ \\
\hline
\end{tabular}

(D) - Massa Seca Total (g)

\begin{tabular}{|c|c|c|c|c|c|c|c|c|}
\hline Pulverização & $4,77 \mathrm{Ac}$ & 8,33 Aa & $6,74 \mathrm{Ab}$ & $6,64 \mathrm{Ab}$ & $6,48 \mathrm{Ab}$ & 7,06 Ab & $5,32 \mathrm{Ac}$ & $35,5 * *$ \\
\hline Imersão & $\begin{array}{l}5,31 \\
\mathrm{Aab}\end{array}$ & 5,82 Bab & $5,99 \mathrm{Ba}$ & $\begin{array}{l}3,92 \\
\text { Bde }\end{array}$ & $5,11 \mathrm{Bbc}$ & 4,46 Bcd & $3,12 \mathrm{Be}$ & $28,5 * *$ \\
\hline $\mathrm{F}$ & $3,93^{\mathrm{ns}}$ & $82,8 * *$ & $7,41 * *$ & $96,7 * *$ & $24,5^{* *}$ & $88,3 * *$ & $63,4 * *$ & ----- \\
\hline
\end{tabular}

Em que: Médias seguidas de mesma letra maiúscula na coluna, e minúscula na linha, não diferem entre si pelo teste de Tukey a 5\% de probabilidade. $*$ e $* *=$ valores significativos a $5 \%$ e $1 \%$ de probabilidade pelo teste $\mathrm{F}$, respectivamente. $\mathrm{ns}=$ valor não significativo a $5 \%$ de probabilidade pelo teste F.

Para a área foliar, todas as doses de etiltrinexapac pulverizadas resultaram em médias superiores às obtidas através da imersão de raízes (Tabela 1-B). Torna-se evidente que a modalidade de imersão das raízes em solução de etiltrinexapac foi prejudicial para o desenvolvimento das folhas e, consequentemente, para a expansão da área foliar das plantas de eucalipto. Já a pulverização do etiltrinexapac, além de não causar efeitos deletérios às plantas, promoveu expansão e emissão de novas folhas. Quando comparada com o resultado das plantas-controle, todas as doses de etiltrinexapac pulverizadas apresentaram efeito 
estimulatório na área foliar. Adicionalmente, a dose de $15 \mathrm{~g}$ i.a. ha ${ }^{-1}$ foi a que proporcionou maior estímulo à expansão da área foliar, alcançando valores $68,1 \%$ maiores que o observado nas plantas-controle. Resultados semelhantes foram observados no estudo conduzido por Pires et al. (2013) ao aplicarem 20 g i.a. ha ${ }^{-1}$ de etiltrinexapac em mudas de Eucalyptus urograndis. Nessa ocasião, os autores observaram um aumento de $20 \%$ na área foliar das plantas de eucalipto avaliadas aos 42 dias após a aplicação de etiltrinexapac.

Figura 1 - Efeito das doses de etiltrinexapac, em duas modalidades de aplicação, sobre a altura $(\mathrm{A}, \mathrm{cm})$, diâmetro do caule $(\mathrm{B}, \mathrm{mm})$, área foliar $\left(\mathrm{C}, \mathrm{cm}^{2}\right)$ e massa seca da raiz $(\mathrm{D}, \mathrm{g})$ das mudas de Eucalyptus urograndis aos 35 dias após a aplicação. Jaboticabal-SP, 2014.

Figure 1 - Effect of trinexapac-ethyl doses, in two application modalities, on the height $(\mathrm{A}, \mathrm{cm})$, stem diameter $(\mathrm{B}, \mathrm{mm})$, leaf area $\left(\mathrm{C}, \mathrm{cm}^{2}\right)$ and root dry mass $(\mathrm{D}, \mathrm{g})$ of Eucalyptus urograndis seedlings at 35 days after application. Jaboticabal, São Paulo state, 2014.

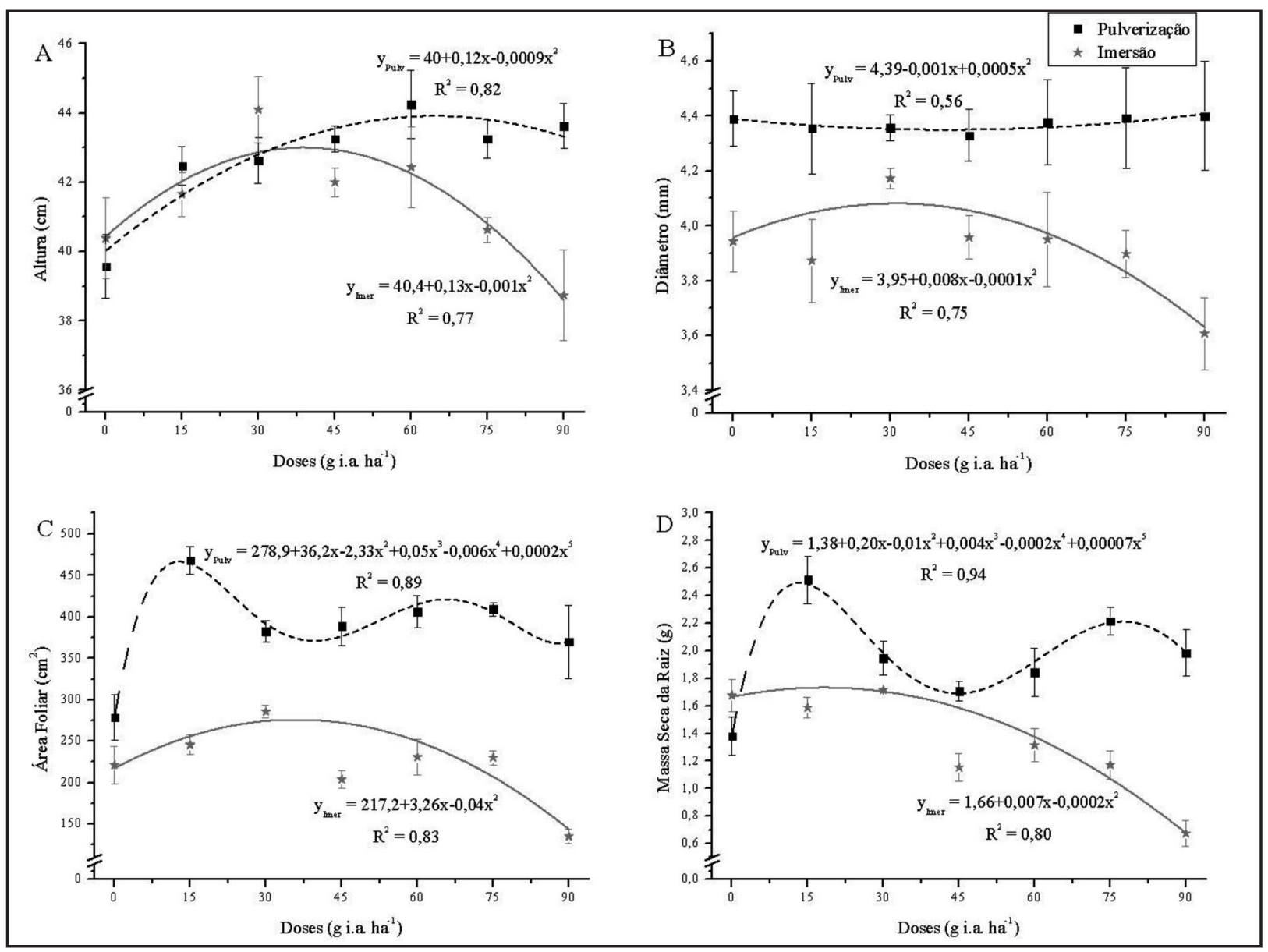

O crescimento inicial das mudas de eucalipto depende da sua capacidade de realização de fotossíntese e, consequentemente, do acúmulo de fotossintatos, os quais ocorrem majoritariamente na porção aérea das plantas (KOZLOWSKI; KRAMER; PALLARDY, 1991). Posteriormente, estes fotossintatos são translocados para as raízes, as quais funcionam como um dreno para os carboidratos produzidos pelas folhas. Com o desenvolvimento da parte aérea estimulado pela aplicação do etiltrinexapac, as raízes podem se desenvolver com mais rapidez e qualidade, promovendo melhor capacidade de "pegamento" no momento do plantio. Ademais, raízes bem estabelecidas conferem maior resistência à estresses bióticos e abióticos e, consequentemente, permitem maior exploração do solo em busca de água e nutrientes, componentes essenciais ao crescimento e estabelecimento inicial das plantas de eucalipto no campo. 
Tabela 2 - Efeito de etiltrinexapac, em duas modalidades de aplicação, sob a altura (cm), diâmetro do caule ( $\mathrm{mm})$, área foliar $\left(\mathrm{cm}^{2}\right)$, massa seca da raiz (MSR, g) e massa seca total (MST, g) das mudas de Eucalyptus urograndis aos 35 dias após a aplicação. Jaboticabal-SP, 2014.

Table 2 - Effect of trinexapac-ethyl in two application modalities, on height $(\mathrm{cm})$, stem diameter (mm), leaf area $\left(\mathrm{cm}^{2}\right)$, root dry mass (MSR, g) and total dry mass (MST, g) of the Eucalyptus urograndis seedlings at 35 days after application. Jaboticabal, São Paulo state, 2014.

\begin{tabular}{lccccc}
\hline Doses (g i.a. ha- $\left.\mathbf{~}^{-1}\right)$ & Altura (cm) & $\begin{array}{c}\text { Diâmetro } \\
(\mathbf{m m})\end{array}$ & $\begin{array}{c}\text { Área Foliar } \\
\left(\mathbf{c m}^{2}\right)\end{array}$ & MSR (g) & MST (g) \\
\hline Pulverização & 42,7 & $4,37 \mathrm{~A}$ & 385,9 & 1,94 & 6,47 \\
Imersão & 41,4 & $3,91 \mathrm{~B}$ & 221,7 & 1,32 & 4,82 \\
\hline 0 & 39,9 & $4,16 \mathrm{~A}$ & 249,6 & 1,52 & 5,04 \\
15 & 42,1 & $4,11 \mathrm{~A}$ & 356,7 & 2,05 & 7,08 \\
30 & 43,3 & $4,26 \mathrm{~A}$ & 333,9 & 1,85 & 6,36 \\
45 & 42,6 & $4,14 \mathrm{~A}$ & 296,3 & 1,43 & 5,28 \\
60 & 43,3 & $4,16 \mathrm{~A}$ & 318,3 & 1,57 & 5,79 \\
75 & 41,9 & $4,14 \mathrm{~A}$ & 319,5 & 1,69 & 5,76 \\
90 & 41,1 & $4,00 \mathrm{~A}$ & 252,2 & 1,32 & 4,22 \\
\hline F (Modalidade) & $18,9^{* *}$ & $42,2^{* *}$ & $477,2^{* *}$ & $140,1^{* *}$ & $252,1^{* *}$ \\
F (Doses) & $9,34^{* *}$ & $0,69^{\text {ns }}$ & $16,5^{* *}$ & $12,9^{* *}$ & $44,8^{* *}$ \\
F (M x D) & $7,24^{* *}$ & $0,94^{\text {ns }}$ & $10,5^{* *}$ & $15,5^{* *}$ & $19,2^{* *}$ \\
CV (\%) & 2,97 & 7,10 & 10,3 & 13,2 & 7,72 \\
\hline
\end{tabular}

Em que: Médias seguidas de mesma letra na coluna não diferem entre si pelo teste de Tukey a 5\% de probabilidade; ** = valores significativos a $1 \%$ de probabilidade pelo teste $\mathrm{F}$; ns = valor não significativo a $5 \%$ de probabilidade pelo teste $\mathrm{F}$; $\mathrm{CV}=\mathrm{Coeficiente} \mathrm{de} \mathrm{variação.}$

Para a modalidade imersão de raízes, o efeito das doses resultou em comportamento diferenciado do apresentado na pulverização foliar (Figura 1-C). A dose de $30 \mathrm{~g}$ i.a. ha ${ }^{-1}$ foi a única que apresentou efeito positivo em comparação às plantas-controle, conferindo acréscimo de $29,2 \%$ na área foliar. Já as doses de 15, 45, 60 e 75 g i.a. ha ${ }^{-1}$, não resultaram em efeito significativo (Figura 1-C). A exceção foi para a aplicação de $90 \mathrm{~g}$ i.a. ha ${ }^{-1}$ de etiltrinexapac, a qual resultou em redução do desenvolvimento da área foliar das plantas de eucalipto, já que, quando comparada às plantas-controle, observou-se decréscimo de $38,8 \%$ (Figura 1-C). Cabe ressaltar que algumas mudas de eucalipto apresentaram acúmulo de antocianina em grande parte das folhas, além de necrose e abscisão foliar. A redução no número de folhas (dados não apresentados) e na área foliar, decorrentes da aplicação do etiltrinexapac via imersão das raízes, evidencia a ação diferenciada do regulador vegetal na parte área e nas raízes das plantas de eucalipto (Figura 1-C).

É possível que a aplicação de etiltrinexapac, através da imersão das raízes, além de reduzir a quantidade de giberelinas ativas (ADAMS et al., 1992), tenha ocasionado alteração na sinalização de outros hormônios, como a auxina, ácido abscísico e o etileno. Estes hormônios vegetais apresentam ação intensa no processo de senescência foliar (TAIZ; ZAIGER, 2013), resultando em degradação de pigmentos fotossintetizantes, redução da produção de fotoassimilados e na consequente abscisão foliar. Desta forma, a imersão das raízes em solução de $90 \mathrm{~g}$ i.a. ha- ${ }^{-1}$ de etiltrinexapac acabou por limitar o crescimento das plantas de eucalipto, como observado para o diâmetro e área foliar (Figura 1). Adicionalmente, Korol e Klein (2002) sugerem que a ação dos inibidores de giberelina podem ressaltar a atividade metabólica ou a efetividade do ácido abscísico e, assim, promover os efeitos de redução no número de folhas e na área foliar, como observados no presente trabalho. 
Figura 2 - Efeito das doses de etiltrinexapac, em duas modalidades de aplicação, sobre a massa seca total (MST, g) das mudas de eucalipto aos 35 dias após a aplicação. Jaboticabal-SP, 2014.

Figure 2 - Effect of trinexapac-ethyl doses, in two application modalities, on the total dry mass (MST,

g) of eucalyptus seedlings at 35 days after application. Jaboticabal, São Paulo state, 2014.

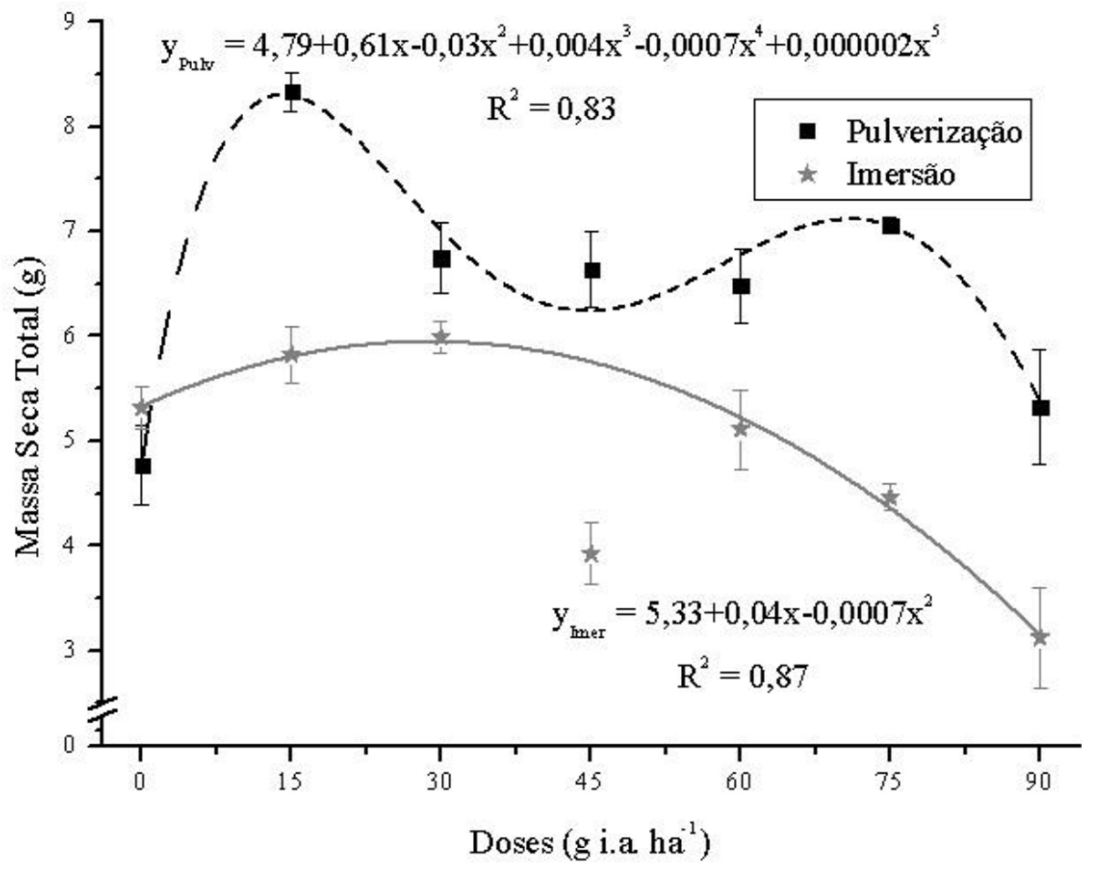

Para a MSR, com exceção da dose de $30 \mathrm{~g}$ i.a. ha ${ }^{-1}$, todas as outras doses aplicadas via pulverização foliar resultaram em maior acúmulo de biomassa do que as doses aplicadas via imersão de raízes (Tabela 1-C). Na modalidade pulverização, as doses de 15 e $75 \mathrm{~g}$ i.a. ha-1 promoveram maior acúmulo de massa nas raízes, resultando, respectivamente, em $81,8 \%$ e $60,1 \%$ de acréscimo, quando comparados às plantascontrole. As demais doses resultaram em acúmulo intermediário de biomassa nas raízes, não diferindo entre si (Figura 1-D). Para a imersão de raízes, foi observado que nenhuma das doses de etiltrinexapac testadas apresentou efeito positivo em relação às plantas-controle (Figura 1-D). Adicionalmente, a dose de $90 \mathrm{~g}$ i.a. ha ${ }^{-1}$ reduziu acentuadamente o desenvolvimento das raízes, resultando em 59,8\% de redução quando comparadas às plantas-controle (Figura 1-D). A restrição do desenvolvimento radicular está relacionada com a redução do crescimento de ramos laterais, altura e diâmetro do caule (ROBBINS; PHARR, 1988; LIU; LATIMER, 1995; VAN IERSEL, 1997). Além disso, as raízes são responsáveis pela absorção de nutrientes e água do solo, constituindo local de biossíntese de hormônios envolvidos com o crescimento da planta, como a citocinina (LETHAM; PALNI, 1983).

Para a MST, com exceção da testemunha, todas as doses aplicadas via pulverização resultaram em maior acúmulo de MST do que as doses aplicadas via imersão de raízes (Tabela 1-D). Na pulverização foliar, novamente verificou-se que a dose de $15 \mathrm{~g}$ i.a. ha ${ }^{-1}$ resultou nos maiores incrementos no acúmulo da massa seca das plantas de eucalipto, resultando em $74,6 \%$ mais biomassa do que as plantas-controle. As demais doses, com exceção da $90 \mathrm{~g}$ i.a. ha ${ }^{-1}$, apresentaram comportamento intermediário, com acréscimo médio de 41,1\% (Figura 2). Corroborando tais resultados, vale ressaltar o trabalho de Pires et al. (2013), o qual reportou um acréscimo de $9 \%$ na MST do eucalipto ao aplicarem 20 g i.a. ha ${ }^{-1}$ de etiltrinexapac. Já Bacha et al. (2017) reportaram resultados ainda mais significativos para esta característica, com aumento médio de $70 \%$ nas doses de 30 e 60 g i.a. ha ${ }^{-1}$, trabalhando com o clone 1407 de Eucalyptus urograndis. Deve-se enfatizar que os autores conduziram o experimento durante 90 dias após a aplicação do produto.

Na modalidade de imersão de raízes, a dose de $90 \mathrm{~g}$ i.a. ha ${ }^{-1}$ resultou em redução no acúmulo de MST, com valores 41,2\% menores em comparação as plantas-controle. A dose de 30 g i.a. ha-1 
apresentou um aumento no acúmulo de MST, com valores $12,8 \%$ maiores em relação às plantascontrole (Figura 2). De maneira geral, a imersão de raízes em crescentes doses de etiltrinexapac resultou na redução gradativa da MST das plantas de eucalipto. A partir dos resultados obtidos para as duas modalidades de aplicação, observa-se que os efeitos das doses aplicadas via pulverização resultaram em promoção das características avaliadas quando comparado aos efeitos da imersão de raízes em soluções de etiltrinexapac (Figuras 1 e 2). De acordo com Rademacher (2000), mesmo com o longo e intensivo processo de seleção e registro dos reguladores vegetais comerciais, ainda existem efeitos não previstos em decorrência da sua aplicação, como o favorecimento e/ou inibição do desenvolvimento e crescimento das plantas, bem como um efeito de neutralidade sem promover ou inibir nenhum processo das plantas tratadas.

$\mathrm{Na}$ aplicação realizada via imersão de raízes, o etiltrinexapac pode ter causado a restrição do desenvolvimento da parte aérea como um reflexo do efeito deletério causado nas raízes. Todavia, cabe ressaltar que o tempo de imersão pode ter influenciado na resposta negativa apresentada pelas plantas, assim como o fato de que o produto possa ter sido adsorvido ao substrato e liberado gradativamente no decorrer do crescimento das mudas durante o período experimental. A absorção do etiltrinexapac ocorre de forma diferenciada nas raízes e nas folhas das plantas, uma vez que a folha se constitui como uma barreira para a entrada do ingrediente ativo e, consequentemente, diminui sua translocação pelo sistema metabólico das mudas de eucalipto.

A pulverização de etiltrinexapac, principalmente na dose de $15 \mathrm{~g}$ i.a. $\mathrm{ha}^{-1}$, resultou no melhor desempenho para as características avaliadas nas plantas de eucalipto. Segundo Fletcher et al. (2000), este benefício ao desenvolvimento das plantas pode ocorrer, já que após a aplicação de reguladores vegetais, os fotoassimilados são translocados para as raízes, principal órgão produtor de citocininas. Como resultado do estímulo de crescimento das raízes, devido à maior disponibilidade de fotossintatos, pode ocorrer aumento da formação de citocinina, que por sua vez, será transportada para a parte aérea, estimulando o crescimento daqueles tecidos vegetais.

Os valores médios para as características apresentadas pelas mudas de eucalipto, em função da aplicação de etiltrinexapac, sugerem um potencial efeito hormético ocasionado pelas doses de 15 e $30 \mathrm{~g}$ i.a. ha ${ }^{-1}$, para ambas as modalidades de aplicação. De acordo com Calabrese e Baldwin (2001), hormesis tem sido encontrada em todos os grupos de organismos, desde bactérias e fungos até plantas e animais superiores. Ainda segundo Calabrese e Baldwin (2002) e Stebbing (1998), é possível afirmar que o efeito hormético representa uma resposta adaptativa baseada no rompimento ambientalmente induzido da homeostase.

Apesar do efeito promotor observado através da aplicação do etiltrinexapac, é necessário que mais pesquisas sejam realizadas para a determinação dos efeitos deste regulador vegetal na cultura do eucalipto. Especificamente, estudos que possam avaliar os efeitos deste produto até o momento da colheita são essenciais, uma vez que, com isso, será possível verificar o ganho real em produtividade e nas características da madeira produzida.

\section{Conclusão}

As doses de $15,30,45,60,75$ e $90 \mathrm{~g}$ i.a. ha ${ }^{-1}$ via pulverização foliar, resultaram em efeito estimulatório ao crescimento de Eucalyptus urograndis (clone GG100) após 35 dias da aplicação do etiltrinexapac.

As doses de 15 e 30 g i.a. ha ${ }^{-1}$, na modalidade imersão das raízes, proporcionaram efeito positivo nas características avaliadas do eucalipto. Aos 35 dias após a aplicação de etiltrinexapac, a dose de $90 \mathrm{~g}$ i.a. ha $^{-1}$ apresentou efeito inibitório ao crescimento do eucalipto na modalidade imersão das raízes.

\section{Agradecimentos}

À FAPESP pela concessão de bolsa de pesquisa para o primeiro autor (processo no 2012/044371), ao CNPq pela concessão de bolsa PQ para o quarto autor, ao Dr. Wilhelm Rademacher pelos valiosos 
comentários acerca do produto químico etiltrinexapac e aos revisores pelos comentários na versão anterior deste manuscrito.

\section{Referências}

ADAMS, R. et al. Studies on the action of the new growth retardant CGA 163935 (cimectacarb). In: KARSEN, C. M.; VAN LOON, L. C.; VREUGDENHIL, D. (Ed.). Progress in plant growth regulation. Dordrecht: Kluwer Academic, 1992. p. 818-827.

BACHA, A. L. et al. Trinexapac-ethyl causes stimulatory effect on the initial growth of Eucalyptus urograndis clones. Journal of Agricultural Science, Toronto, v. 9, n. 10, p. 189-197, 2017.

BELZ, R. G.; DUKE S. O. Herbicides and plant hormesis. Pest Management Science, Hoboken, v. 70, n. 5, p. 698-707, 2014.

CALABRESE, E. J.; BALDWIN, L. A. Defining hormesis. Human and Experimental Toxicology, London, v. 21, p. 91-97, 2002.

CALABRESE, E. J.; BALDWIN, L. A. Hormesis: a generalizable and unifying hypothesis. Critical Reviews in Toxicology, Oxon, v. 31, p. 353-424, 2001.

CARVAlHO, L. B.; ALVES, P. L. C. A.; DUKE, S. O. Hormesis with glyphosate depends on coffee growth stage. Proceedings of the Brazilian Academy of Science, Rio de Janeiro, v. 85, n. 2, p. 813-821, 2013.

CEDERGREEN, N.; OLESEN, C. F. Can glyphosate stimulate photosynthesis? Pesticide Biochemistry and Physiology, San Diego, v. 96, n. 3, p. 140-148, 2010.

ERVIN, E. H.; KOSKI, A. J. Trinexapac-ethyl increases Kentucky bluegrass leaf cell density and chlorophyll concentration. HortScience, Alexandria, v. 36, n. 4, p. 787-789, 2001.

FLETCHER, R. A. et al. Triazoles as plant growth regulators and stress protectants. Horticultural Reviews, Oxford, v. 24, n. 1, p. 55-138, 2000.

HISAMATSU, T. et al. Effect of gibberellin A4 and GA biosynthesis inhibitors on growth and flowering of stock [Matthiola incana (L.) R. Br.]. Journal of the Japanese Society for Horticultural Science, Kyoto, v. 64, n. 4 , p. 537-543, 1998.

INDÚSTRIA BRASILEIRA DE ÁRVORES. Relatório anual de 2016. Brasília: IBÁ, 2016. Disponível em: http://iba.org/images/shared/Biblioteca/IBA_RelatorioAnual2016_.pdf. Acesso em: 25 jan. 2017.

KOROL, L.; KLEIN, J. D. Profiles of trinexpac-ethil - and ABA - induced heat-stable proteins in embrionic axes of wheat seeds. Euphytica, Dordrecht, v. 126, p. 77-81, 2002.

KOZLOWSKI, T. T.; KRAMER, P. J.; PALLARDY, S. G. The physiological ecology of woody plants. San Diego: Academic Press, 1991.

LETHAM, D. S.; PALNI, L. M. S. The biosynthesis and metabolism of cytokinins. Annual Review of Plant Physiology, Palo Alto, v. 34, p. 163-197, 1983.

LIU, A.; LATIMER, J. G. Water relations and abscisic acid levels of watermelon as affected by rooting volume restriction. Journal of Experimental Botany, Oxford, v. 46, n. 289, p. 1011-1015, 1995.

PEREIRA, F. C. M. et al. Response of eucalyptus (Eucalyptus urograndis) plants at different doses of 
glyphosate. Journal of Agricultural Science, Toronto, v. 5, n. 1, p. 66-74, 2013.

PIRES, R. N. et al. Effects of the simulated drift of ripeners on Eucalyptus urograndis. Journal of Agricultural Science, Toronto, v. 5, n. 12, p. 78-86, 2013.

RADEMACHER, W. Chemical regulators of gibberellin status and their application in plant production. Annual Plant Reviews, Chichester, v. 49, p. 359-403, 2016.

RADEMACHER, W. Growth retardants: effects on giberellin biosynthesis and other metabolic pathways. Annual Review of Plant Physiology and Plant Molecular Biology, Palo Alto, v. 51, p. 501-531, 2000.

RAJALA, A. et al. Effects of applying stem-growth regulators to leaves on root elongation by seedlings of wheat, oat and barley: mediation by ethilene. Plant Growth Regulation, Dordrecht, v. 38, n. 1, p. 51-59, 2002.

ROBBINS, N. S.; PHARR, D. M. Effect of restricted root growth on carbohydrate metabolism and whole plant growth of Cucumis sativus L. Plant Physiology, Rockville, v. 87, p. 409-413, 1988.

STEBBING, A. R. D. A theory of growth hormesis. Mutation Research, Amsterdam, v. 403, p. 249-258, 1998.

SOUTHAM, C. M.; ERLICH, J. Effects of extract of western red-cedar heartwood on certain wooddecaying fungi in culture. Phytopathology, Saint Paul, v. 33, p. 517-524, 1943.

TAIZ, L.; ZEIGER, E. Fisiologia vegetal. 5. ed. Porto Alegre: Artmed, 2013.

VAN IERSEL, M. Root restriction effects on growth and development of salvia (Salvia splendens). HortScience, Alexandria, v. 32, n. 7, p. 1186-1190, 1997.

VELINI, E. D. et al. Glyphosate at low doses can stimulate plant growth. Pest Management Science, Hoboken, v. 64, n. 4, p. 489-496, 2008. 